\title{
SCIENTIFIC REPORTS

\section{OPEN Vanadium Phosphorus Oxide/ Siliceous Mesostructured Cellular Foams: efficient and selective for sustainable acrylic acid production via condensation route}

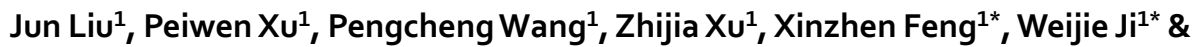 \\ Chak-Tong $\mathrm{Au}^{2}$
}

A new type of supported vanadium phosphorus oxide (VPO) with self-phase regulation was simply fabricated (organic solvent free) for the first time by depositing the specific VPO precursor $\mathrm{NH}_{4}\left(\mathrm{VO}_{2}\right)$ $\mathrm{HPO}_{4}$ onto the Siliceous Mesostructured Cellular Foams (MCF) with controlled activation. The resulting materials were found to be highly efficient and selective for sustainable acrylic acid (AA) plus methyl acrylate (MA) production via a condensation route between acetic acid (HAC) and formaldehyde ( $\mathrm{HCHO}$ ). A (AA + MA) yield of $83.7 \%$ ( $\mathrm{HCHO}$ input-based) or a (AA + MA) selectivity of $81.7 \%$ (converted $\mathrm{HAc}$-based) are achievable at $360^{\circ} \mathrm{C}$. The systematic characterizations and evaluations demonstrate a unique surface regulation occurring between the $\mathrm{MCF}$ and the $\mathrm{NH}_{4}\left(\mathrm{VO}_{2}\right) \mathrm{HPO}_{4}$ precursor. $\mathrm{NH}_{3}$ release upon activation of $\mathrm{NH}_{4}\left(\mathrm{VO}_{2}\right) \mathrm{HPO}_{4}$ precursor together with adsorption of $\mathrm{NH}_{3}$ by MCF automatically induces partial reduction of $\mathrm{V}^{5+}$ whose content is fine-tunable by the VPO loading. Such a functionalization simultaneously modifies phase constitution and surface acidity/basicity of catalyst, hence readily controls catalytic performance.

Acrylic acid (AA) together with methyl acrylate (MA) were widely applied for producing adhesives, plastics, PAN fibers, hydrogel, biomimetic materials, coatings etc. ${ }^{1-3}$. At present, the traditional way to make AA involves successive oxidation of propylene ${ }^{4-9}$. The propylene feedstock, however, is closely associated with the oil reserve and thought to be non-sustainable, hence an enthusiasm raised by the volatile of crude oil price to explore alternative production route of AA through sustainable resources becomes stronger ${ }^{10-12}$. In recent years, López Nieto and co-workers systematically studied the oxidehydration of glycerol to AA through a one-pot process ${ }^{13-15}$. Furthermore, AA manufacture through the condensation between $\mathrm{HCHO}$ and $\mathrm{HAc}$ is also considered as a promising approach. Currently, both HCHO and HAc are made from methanol, whereas HAc is largely produced via catalytic carbonylation of methanol. On the other hand, $\mathrm{HCHO}$ is fabricated via methanol oxidation. At present, methanol is mainly originated from natural gas/coal, and largely distributed in Asian and North America. As a result, both HAc and HCHO are getting low-priced. Due to an obvious over-production capacity of HAc, it is highly desirable to explore a new process transforming HAc to the value-added chemical such as AA. Researchers have devoted their efforts to the condensation route employing $\mathrm{HAc}$ and $\mathrm{HCHO}^{16-19}$.

Typically, the gas phase condensation using $\mathrm{HCHO}$ and HAc can be catalyzed by solid acids and/or bases, or acid-base bi-functional catalysts ${ }^{20-22}$. Among the basic catalysts, a variety of cesium supported catalysts, using $\mathrm{SiO}_{2}$ and SBA-15 as supports, were investigated for the objective reaction ${ }^{22,23}$. Real practice of this kind of catalyst, however, was technically difficult since the AA/MA yield is not high enough and the alkali metal oxides are sensitive to atmosphere. Ai et al. found out that the acid-base bi-functional catalyst $\mathrm{V}_{2} \mathrm{O}_{5}-\mathrm{P}_{2} \mathrm{O}_{5}$ outperformed the acidic counterparts ${ }^{18}$.

${ }^{1}$ Key Laboratory of Mesoscopic Chemistry, MOE, School of Chemistry and Chemical Engineering, Nanjing University, Nanjing, 210023, China. '2Department of Chemistry, Hong Kong Baptist University, Kowloon Tong, Hong Kong. *email: fxz@nju.edu.cn; jiwjnju@yahoo.com 


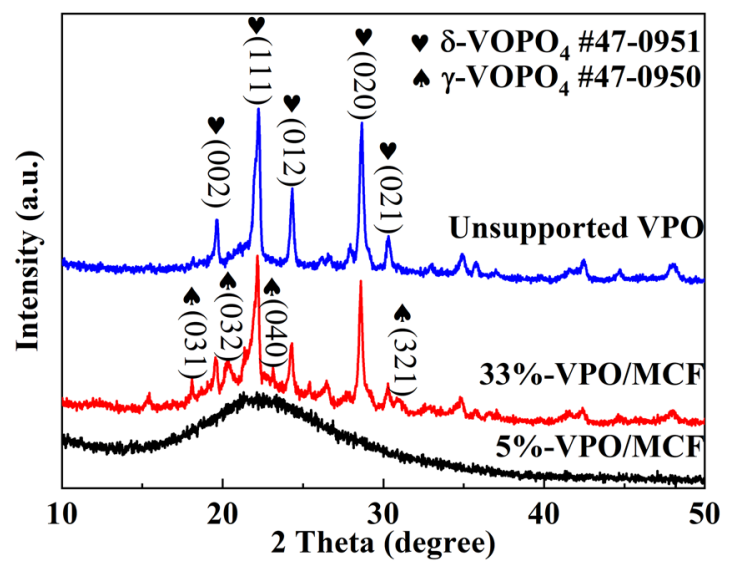

Figure 1. XRD patterns of the representative catalysts.

The vanadium phosphorus oxide (VPO) type catalyst is versatile for selective oxidation of light alkanes such as $n$-butane and propane ${ }^{24,25}$. In recent years, people paid much attention to the condensation route over the VPO type catalyst. Yang et al. ${ }^{26}$ reported that the relative V/P content was curial for catalytic behavior. Ji and co-workers ${ }^{20}$ observed a VPO catalyst containing a great amount of $\delta$ - $\mathrm{VOPO}_{4}$ species efficient for the condensation route. Furthermore, Wang et al. ${ }^{27}$ found that the $\mathrm{V}^{4+}$ and $\mathrm{V}^{5+}$ species in the $(\mathrm{VO})_{2} \mathrm{P}_{2} \mathrm{O}_{7}$ and $\mathrm{VOPO}_{4}$ phase respectively gives the critical $\mathrm{V}^{4+}$ to $\mathrm{V}^{5+}$ ratio influential on catalytic activity of the VPO type catalyst. The complexity in phase composition, oxidation state of $\mathrm{V}$, and surface atomic ratio $\mathrm{P}$ to $\mathrm{V}$ of $\mathrm{VPO}$ catalyst requires a deeper understanding the structure-performance correlation for the target reaction.

So far, a few supported VPO systems have been reported for the target reaction ${ }^{28-31}$. Hu et al. ${ }^{31}$ reported a series of supported VPOs on $\mathrm{SiO}_{2}, \mathrm{SBA}-15$, and HZSM-5, and found that the kind of support has a substantial impact on the acid-base property of catalyst, showing distinct catalytic behavior as a result. Zhao et al. ${ }^{28}$ investigated the condensation reaction over the VPO supported on $\mathrm{TiO}_{2}, \mathrm{SiO}_{2}, \mathrm{Sb}_{2} \mathrm{O}_{3}, \gamma-\mathrm{Al}_{2} \mathrm{O}_{3}, \mathrm{ZrO}_{2}, \mathrm{Nb}_{2} \mathrm{O}_{5}$, and $\eta-\mathrm{Al}_{2} \mathrm{O}_{3}$, and found out that the support type would significantly modify the structure and composition of active phase as well as the acid-base characteristics.

Three-dimensional (3D) cellular solid foams have been widely used in the field of materials engineering such as electrochemical porous electrodes ${ }^{32,33}$. Siliceous Mesostructured Cellular Foams (MCF), with well-defined uniform ultra-large mesopores and surface area as well as aerogel-like 3D pore channels were utilized in various applications such as catalysis, separation, and adsorption ${ }^{34}$. Different from bulk $\mathrm{SiO}_{2}$ or porous materials with $2 \mathrm{D}$ pore channels (MCM-41 and SBA-15), MCF is a new class of 3D hydrothermally robust materials with ultra-large mesopores (up to $50 \mathrm{~nm}$ ). In terms of the textural and framework structure, the MCF materials resemble aerogels and comprise uniform spherical cells interconnected by windows with a narrow size distribution. These novel pore characteristics of MCF provide more open porous networks, allowing accommodation of more guest species (such as VPO herein), and more accessible contact between reactants and active sites and thus improved diffusion ability ${ }^{35,36}$. In this study, the choice of MCF as support was not limited to these benefits, the MCF can function the $\mathrm{NH}_{3}$-assisted $\mathrm{V}^{5+}$ reduction and vary the phase constitution and consequently the surface $\mathrm{V}^{4+} / \mathrm{V}^{5+}$ ratio, which in turn simultaneously modifies the surface acidity of catalyst and hence controls the reaction performance. Therefore, a new type of supported VPO catalyst can be developed with a feature of self-regulation of active phase and surface acidity by employing $\mathrm{NH}_{4}\left(\mathrm{VO}_{2}\right) \mathrm{HPO}_{4}$ as the VPO precursor and systematically varying its loading on MCF support. The quantity of released $\mathrm{NH}_{3}$ and the degree of $\mathrm{V}^{5+}$ reduction and thus the surface ratio of $\mathrm{V}^{4+} / \mathrm{V}^{5+}$ together with the corresponding catalyst surface acidity can be fine-tuned in sample serial. In such a way, catalyst nature and activity can be systematically controlled. Upon the characterizations using BET, XRD, XPS, $\mathrm{NH}_{3}-\mathrm{TPD}$, plus Pyridine-IR, detailed structure-performance relationship can be established.

In most of previous studies on the target reaction, the performance was evaluated in terms of the HCHO-based yield. Though it is useful, while insufficient to reveal the overall reaction process, especially in view of the practical application. This is because HAc is commonly excess to HCHO in great amount, and the by-products such as acetone and $\mathrm{CO}_{\mathrm{x}}$ are largely originated from HAc. In this study, we calculated the HAc-based (AA+MA) selectivity for the first time as well as the overall carbon balance which is essential to get a complete picture of the reaction but did not appear in the early literature.

\section{Results and Discussion}

XRD analysis. The XRD patterns of various catalysts were displayed in Fig. 1. The supports could largely affect the structure of supported catalysts ${ }^{28}$. All the diffraction lines can be ascribed to the $\delta-\mathrm{VOPO}_{4} \mathrm{phase}$ (PDF\#47-0951) and no other peak was observed. It means the V, P-containing precursor $\left(\mathrm{NH}_{4}\left(\mathrm{VO}_{2}\right) \mathrm{HPO}_{4}\right)$ was transformed to nearly pure $\delta-\mathrm{VOPO}_{4}$ entity under the employed activation conditions. Notably, the phase structure was obviously changed after activation when this VPO precursor was deposited on MCF. The XRD pattern of $5 \%-\mathrm{VPO} / \mathrm{MCF}$ shows only one broad peak centered at $2 \theta=15-35^{\circ}$, characteristic of siliceous materials $^{22}$. The VPO entity of low loading is undetectable on the MCF surface. It is either in amorphous state or well-dispersed and difficult to be distinguished by XRD. As the VPO loading is raised to 33\%, all the diffraction lines can be assigned to the $\delta-\mathrm{VOPO}_{4}(\mathrm{PDF} \# 47-0951)$ and $\gamma-\mathrm{VOPO}_{4}(\mathrm{PDF} \# 47-0950)$ phases. Compared to the 


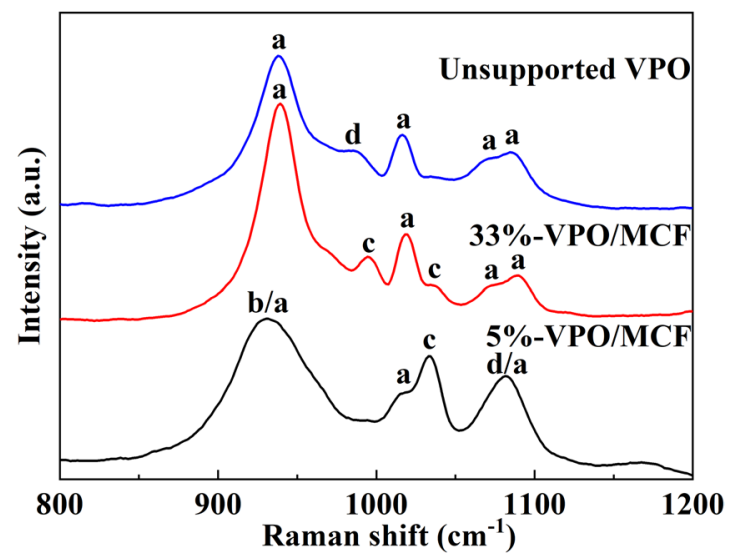

Figure 2. Raman spectra of the catalysts, a: $\delta-\mathrm{VOPO}_{4}$, b: $(\mathrm{VO})_{2} \mathrm{P}_{2} \mathrm{O}_{7}, \mathrm{c}: \gamma-\mathrm{VOPO}_{4}$, and d: $\beta-\mathrm{VOPO}_{4}$.

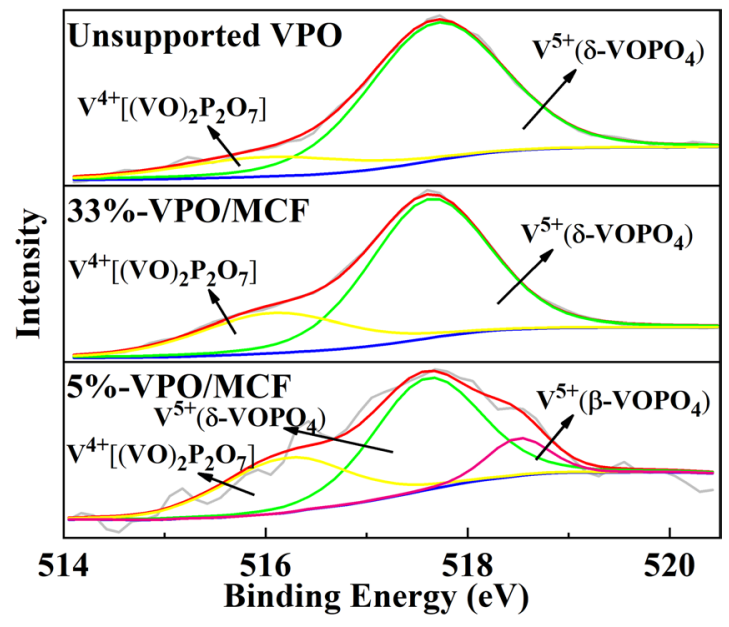

Figure 3. Curve-fitting analysis of the $\mathrm{V} 2 \mathrm{p}_{3 / 2}$ peaks of the catalysts.

unsupported VPO sample, a VPO/MCF sample comprises binary $\mathrm{VOPO}_{4}$ phases after thermal activation of dispersed $\mathrm{NH}_{4}\left(\mathrm{VO}_{2}\right) \mathrm{HPO}_{4}$ precursor on $\mathrm{MCF}\left[\mathrm{NH}_{4}\left(\mathrm{VO}_{2}\right) \mathrm{HPO}_{4} \rightarrow \mathrm{VOPO}_{4}+\mathrm{NH}_{3}+\mathrm{H}_{2} \mathrm{O}\right]$. Interestingly, according to our previous study ${ }^{37}$, a binary-phase VPO catalyst consisting of $\delta-\mathrm{VOPO}_{4}$ and $\gamma-\mathrm{VOPO}_{4}$ exhibited promising catalytic performance. Therefore, the $33 \%-\mathrm{VPO} / \mathrm{MCF}$ with the spontaneously generated $\delta-\mathrm{VOPO}_{4}$ and $\gamma-\mathrm{VOPO}_{4}$ phases would be highly favorable owing to the unique inter-phase conjunction for the reaction ${ }^{37}$.

Raman analysis. Figure 2 exhibits the Raman spectra of various catalysts. Two distinct spectroscopic regions can be classified for various $\mathrm{VOPO}_{4}$ species $^{38}$, namely, the range of $850-1200 \mathrm{~cm}^{-1}$ corresponding to the $\mathrm{P}-\mathrm{O}$ and $\mathrm{V}-\mathrm{O}$ stretching modes. According to the previous reports ${ }^{38,39}$, the intensive band of ca. $936 \mathrm{~cm}^{-1}$ together with the weak bands at 1020,1075 , and $1090 \mathrm{~cm}^{-1}$ are characteristic of $\delta-\mathrm{VOPO}_{4}$ species for the unsupported VPO catalyst, and the weak band of $986 \mathrm{~cm}^{-1}$ is due to $\beta-\mathrm{VOPO}_{4}$. Clearly, the unsupported VPO contains most of $\delta-\mathrm{VOPO}_{4}$ plus minor $\beta-\mathrm{VOPO}_{4}$ phases. Surprisingly, as shown in Fig. 2, the VPO entities in 5\%-VPO/MCF are found to be $(\mathrm{VO})_{2} \mathrm{P}_{2} \mathrm{O}_{7}, \gamma-\mathrm{VOPO}$, and $\beta-\mathrm{VOPO}_{4}$, whereas the $\delta-\mathrm{VOPO}_{4}$ is considerably reduced. The dominant $\delta-\mathrm{VOPO}_{4}$ together with minor $\gamma-\mathrm{VOPO}_{4}$ is confirmed in $33 \%-\mathrm{VPO} / \mathrm{MCF}$, consistent with the corresponding $\mathrm{XRD}$ observation. In terms of the XRD and Raman measurements, one can figure out that the pure catalyst precursor $\mathrm{NH}_{4}\left(\mathrm{VO}_{2}\right) \mathrm{HPO}_{4}$ is essentially transformed into $\delta-\mathrm{VOPO}_{4}$ upon activation. In a low loading sample such as $5 \%$-VPO/MCF, $(\mathrm{VO})_{2} \mathrm{P}_{2} \mathrm{O}_{7}, \gamma-\mathrm{VOPO}_{4}$, and $\beta-\mathrm{VOPO}_{4}$ plus remarkably reduced $\delta$ - $\mathrm{VOPO}_{4}$ co-exist; whereas in a high loading sample such as $33 \%-\mathrm{VPO} / \mathrm{MCF}$, dominant $\delta-\mathrm{VOPO}_{4}$ plus minor $\gamma-\mathrm{VOPO}_{4}$ co-exist. Obviously, significant change in VPO phase composition would result in notable variation in $\mathrm{I}_{\mathrm{V}}{ }^{4+} / \mathrm{I}_{\mathrm{V}}{ }^{5+}$ (intensity ratio of $\mathrm{V}^{4+}$ and $\mathrm{V}^{5+}$ species). According to literature ${ }^{20}$, a VPO catalyst with a suitable $\mathrm{I}_{\mathrm{V}}{ }^{4+} / \mathrm{I}_{\mathrm{V}}{ }^{5+}$ value would outperform the one with simplex valence state.

XPS analysis. The XPS analysis tells the surface elemental composition on the different catalysts. The binding energies were calibrated against $284.6 \mathrm{eV}^{40}$. The spectra of unsupported VPO and 33\%-VPO/MCF (Fig. 3) can be deconvoluted into two separate peaks centered at 517.6 and $516.0 \mathrm{eV}$, corresponding to the signal of $\mathrm{V}^{5+}$ $2 \mathrm{p}_{3 / 2}$ and $\mathrm{V}^{4+} 2 \mathrm{p}_{3 / 2}$, respectively ${ }^{41,42}$. The spectrum of $5 \%$-VPO/MCF can be deconvoluted into three components centered at $518.7,517.6$, and $516.0 \mathrm{eV}$, corresponding to the signal of $\mathrm{V}^{5+} 2 \mathrm{p}_{3 / 2}$ associated with $\beta-\mathrm{VOPO}_{4}$ and 


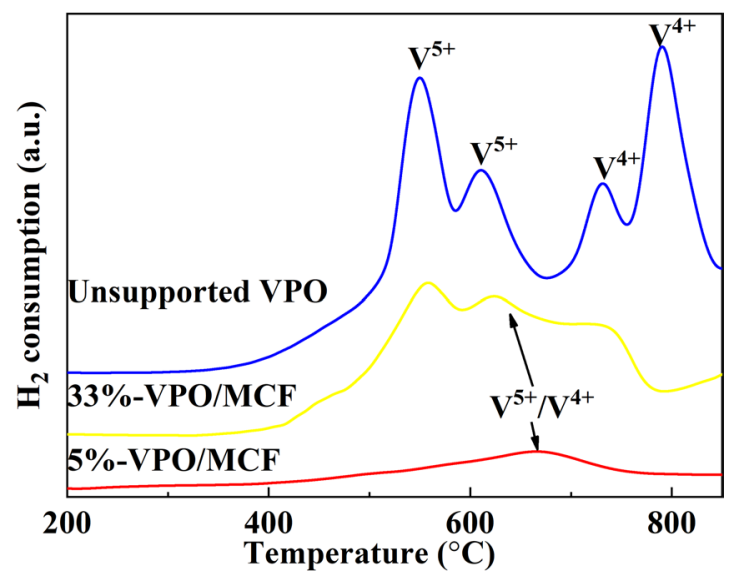

Figure 4. $\mathrm{H}_{2}$-TPR profiles of the representative catalysts.

$\delta$ - $\mathrm{VOPO}_{4}$ as well as that of $\mathrm{V}^{4+} 2 \mathrm{p}_{3 / 2}$, respectively ${ }^{43}$. The XPS results appear consistent with the XRD and Raman observations. Moreover, the surface elemental composition of different catalysts was estimated, and the data were presented in Table S1 (Supplementary Information). The measured surface P/V ratios are higher than the nominal value, owing to the common P enrichment on the VPO type catalyst ${ }^{44-46}$. Note also that, the surface P/V ratio of $5 \%$-VPO/MCF and 33\%-VPO/MCF is higher than that of unsupported VPO catalyst, indicating that the presence of MCF further intensifies the P enrichment on the MCF supported catalysts. On the other hand, the $\mathrm{V}^{4+} / \mathrm{V}^{5+}$ ratio of unsupported $\mathrm{VPO}$ is approximately 0.2 , whereas the $\mathrm{V}^{4+} / \mathrm{V}^{5+}$ ratio increases with increasing VPO loading over the supported catalysts. It is understandable since the released $\mathrm{NH}_{3}$ from the decomposition of $\mathrm{NH}_{4}\left(\mathrm{VO}_{2}\right) \mathrm{HPO}_{4}$ precursor would be captured by $\mathrm{MCF}$, and the reduction of $\mathrm{V}^{5+}$ to $\mathrm{V}^{4+}$ is promoted by the adsorbed $\mathrm{NH}_{3}$. It is worth pointing out that, the amount of adsorbed $\mathrm{NH}_{3}$ on the MCF surface is dependent on the VPO loading (i.e. the $\mathrm{NH}_{4}\left(\mathrm{VO}_{2}\right) \mathrm{HPO}_{4}$ content) as well as the free MCF surface; whereas the reduction of $\mathrm{V}^{5+}$ to $\mathrm{V}^{4+}$ is governed by the amount of adsorbed $\mathrm{NH}_{3}$ and the dispersion state of VPO entity. Apparently, a higher degree of $\mathrm{V}^{5+}$ to $\mathrm{V}^{4+}$ reduction occurs on a supported VPO with a relatively low VPO loading.

$\mathrm{H}_{2}$-TPR analysis. Figure 4 exhibits the $\mathrm{H}_{2}$-TPR profiles of different catalysts. The peaks appearing in the $400-$ $650^{\circ} \mathrm{C}$ range are ascribable to the $\mathrm{V}^{5+}$ reduction, whereas the peaks of $700-850^{\circ} \mathrm{C}$ are owing to the $\mathrm{V}^{4+}$ reduc$\operatorname{tion}^{47,48}$. Notably, there is only one broad peak in the $400-800^{\circ} \mathrm{C}$ range on both $33 \%-\mathrm{VPO} / \mathrm{MCF}$ and $5 \%$-VPO/ MCF. The results imply the existence of $\mathrm{V}^{4+}$ and $\mathrm{V}^{5+}$ species in the two supported catalysts. This agrees with XPS study. On the other hand, there are two peaks in the range of $400-650{ }^{\circ} \mathrm{C}$ for the unsupported VPO, attributable to the $\mathrm{V}^{4+} / \mathrm{V}^{5+}$ reduction in $\delta-\mathrm{VOPO}_{4}$ and $\beta-\mathrm{VOPO}_{4}$, as revealed by the Raman/XPS investigations. The two peaks within $700-850^{\circ} \mathrm{C}$ can be owing to the reduction of two kinds of structurally distinct $\mathrm{V}^{4+}$ species.

$\mathrm{N}_{2}$ sorption measurement analysis. The $\mathrm{N}_{2}$ adsorption-desorption isotherms of different VPO/MCF were measured at $77 \mathrm{~K}$. MCF, 5\%-VPO/MCF, and 33\%-VPO/MCF exhibit type IV isotherms ${ }^{49}$ with typical H1 type hysteresis loops at the relative pressure of 0.6-1.0 (not shown). The results suggest that the MCF support retains three-dimensional (3D) mesopores even at a VPO loading of $33 \%{ }^{36}$. As shown in Table S2 (Supplementary Information), the average pore diameter increases whereas the surface area and pore volume decreases with increasing VPO loading. This is likely due to the existence of VPO components inside the pores and thus the pore-plug as a result. Notably, as the VPO loading is increased, the aggregation of plate-like VPO particles occurs, generating the slit-shaped pores and causing increment in pore diameter.

Pyridine-adsorption FTIR analysis. The type and relative amount of acid sites has been characterized by FTIR spectroscopy using pyridine as a probe. The Brønsted and Lewis acid sites can be identified in view of the IR bands at ca. $1540 / 1640 \mathrm{~cm}^{-1}$ and $1439 / 1447 / 1580 / 1597 \mathrm{~cm}^{-1}$, respectively. The co-presence of B/L acid sites can be confirmed by the IR band of $1490 \mathrm{~cm}^{-150}$. As shown in Fig. S1, the IR bands at 1439 and $1594 \mathrm{~cm}^{-1} \mathrm{can} \mathrm{be}^{-1}$ assigned to the Lewis acid sites over the unsupported VPO. Similarly, the IR bands of 1447 and $1595 \mathrm{~cm}^{-1}$ over pure MCF, 5\%-VPO/MCF, and 33\%-VPO/MCF are attributable to the $\mathrm{L}$ acid sites ${ }^{50-53}$. Notably, only Lewis acid sites essentially exist on the MCF support and this L-type acid site has little contribution to the target reaction ${ }^{54}$. Both $\mathrm{B}$ and $\mathrm{L}$ acid sites co-exist over 5\%-VPO/MCF, 33\%-VPO/MCF, and unsupported VPO, but the fraction of $\mathrm{B}$ acid sites in the overall acid sites gradually decreases with increasing VPO content. Interestingly, the nature of $\mathrm{L}$ acid sites over MCF support and VPO entity is distinct in view of their IR band shift; in other words, co-existence of B and L acid sites on the VPO entity could account for the observed catalytic activity, whereas the variation in the ratio of $\mathrm{B} / \mathrm{L}$ acid sites is also responsible for the distinct catalytic behavior of supported/unsupported VPOs.

$\mathrm{NH}_{3}-/ \mathrm{CO}_{2}$-TPD analysis. The catalyst acid/base characters were further investigated using $\mathrm{NH}_{3}-/ \mathrm{CO}_{2}-\mathrm{TPD}$ and the results are shown in Figs. 5 and S2 and Table S3 (Supplementary Information). As shown in Fig. 5, the $\mathrm{NH}_{3}$ desorption peaks over $5 \%$-VPO/MCF and $33 \%$-VPO/MCF emerges at $150-275^{\circ} \mathrm{C}$, suggesting the presence of weak acid sites on the MCF supported VPO catalysts ${ }^{29}$. On the unsupported VPO, the $\mathrm{NH}_{3}$ desorption peaks 


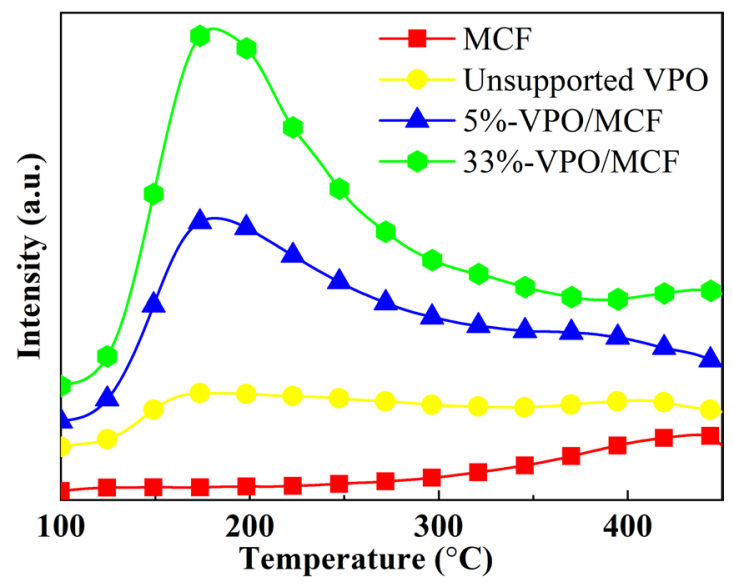

Figure 5. $\mathrm{NH}_{3}$-TPD profiles of the catalysts.

appear at $150-300^{\circ} \mathrm{C}$ and $350-450^{\circ} \mathrm{C}$, indicating the existence of weak and medium strong acid sites. Over pure MCF, no peak observed in the range of $150-300^{\circ} \mathrm{C}$, suggesting that the weak acid sites presenting on $5 \%-\mathrm{VPO} /$ MCF and 33\%-VPO/MCF are not originated from $\mathrm{MCF}^{31}$. Obviously, the quantity of acid sites on 5\%-VPO/ $\mathrm{MCF}$ and 33\%-VPO/MCF is remarkably greater than that of the unsupported counterpart, and the acidity also increases with increasing VPO loading. The application of MCF not only changes the strength but also enhances the quantity of acid sites. The reason for that change in surface acidity is mainly due to the variation in surface $\mathrm{V}^{4+} / \mathrm{V}^{5+}$ ratio as revealed by XPS and $\mathrm{H}_{2}$-TPR investigations. Notably, there is no $\mathrm{NH}_{3}$ desorption peak over MCF in the $300-450^{\circ} \mathrm{C}$ range, indicating $\mathrm{NH}_{3}$ can rather strongly adsorb on the MCF support. Be aware of the fact that during the activation of the MCF supported VPOs, accompanying with the decomposition of the $\mathrm{NH}_{4}\left(\mathrm{VO}_{2}\right)$ $\mathrm{HPO}_{4}$ precursor, the released $\mathrm{NH}_{3}$ can be resident in fairly high concentration on the MCF surface, which in turn modifies the surface $\mathrm{V}^{4+} / \mathrm{V}^{5+}$ ratio via a $\mathrm{NH}_{3}$-induced reduction of $\mathrm{V}^{5+}$ to $\mathrm{V}^{4+}$.

As Fig. S2 (Supplementary Information) showed, the $\mathrm{CO}_{2}$ desorption peaks over the pure VPO and MCF centered at around $450{ }^{\circ} \mathrm{C}$, indicating that the strong basic sites exist on the unsupported VPO as well as the MCF support. Over 5\%-VPO/MCF, two $\mathrm{CO}_{2}$ desorption peaks at 241 and $446^{\circ} \mathrm{C}$ can be observed; whereas over $33 \%$-VPO/MCF, two $\mathrm{CO}_{2}$ desorption peaks at 198 and $421^{\circ} \mathrm{C}$ can be found, indicating that both supported catalysts have weak and strong basic sites. Clearly, the introduction of MCF changes not only surface acidity but surface basicity as well. According to the previous study ${ }^{31}$, the basicity of VPO can be significantly affected by the $\mathrm{P} / \mathrm{V}$ ratio. As revealed by the XPS results in this study, 33\% VPO/MCF shows the highest surface $\mathrm{P} / \mathrm{V}$ ratio. In line with the $\mathrm{CO}_{2}$-TPD profiles over $33 \%-\mathrm{VPO} / \mathrm{MCF}$, it is reasonable to deduce that a higher $\mathrm{P} / \mathrm{V}$ ratio corresponds to a higher density of weak basic sites. If the catalyst acidity and basicity is considered together to correlate with the catalyst performance; clearly, higher concentration of weak acidic and basic sites are responsible for better catalytic activity.

Catalytic performance. Effect of VPO loading. A typical condensation of formaldehyde with acetic acid catalyzed by VPO/MCF with various VPO loading was investigated at atmospheric pressure, a mixture of acetic acid and formaldehyde $(15.25 \mathrm{mmol}$ to $6.1 \mathrm{mmol})$ was fed into the reactor $(1.33 \mathrm{~mL} / \mathrm{h})$. The reaction temperature was $360^{\circ} \mathrm{C}$ and the pre-mixed $\mathrm{N}_{2}$ and air (total flow rate $=40 \mathrm{~mL} / \mathrm{min}$, and the oxygen flow rate is $0.9 \mathrm{~mL} / \mathrm{min}$ ) was used as a carrier. The MCF supported VPO catalysts with the VPO loadings of 10, 15, 20, and 50\% were also prepared and evaluated to identify the optimum VPO content. As shown in Fig. 6, the MCF itself (loading capacity $=0 \%$ ) shows no catalytic activity under the applied conditions and the (AA+MA) selectivity (HAc-based) was kept rising as the loading capacity increased to $100 \%$ (pure VPO), indicating that the activity was essentially originated from the VPO entities. In addition, the yield of (AA + MA) (HCHO-based) and HAc conversion increased notably with increasing VPO loading from 5\% till 33\% and then decreased with further increasing VPO loading (50\%), suggesting that an optimal VPO loading is $33 \%$ at which the maximum VPO dispersion is achieved. According to our previous studies ${ }^{16,20,26}$, it has been verified that the surface acid-base property is critical to determine the catalytic performance of the current reaction. And according to the characterization results (see below), it is known that the presence of MCF together with VPO loading shows a significant influence on the surface $\mathrm{P} / \mathrm{V}$ and $\mathrm{V}^{4+} / \mathrm{V}^{5+}$ ratios, which in turn modifies the surface acidity and basicity of catalyst accordingly.

Effect of HCHO/HAc feedstock. The production of AA (MA) through the condensation of HCHO with HAc has received substantial interest from both academic and industrial communities. Formalin ${ }^{20,26}$, trioxymethyl$\mathrm{ene}^{55}$, and dimsethoxymethane ${ }^{56}$ were employed as formaldehyde source. As shown in Fig. S3 (Supplementary Information), a mixture of acetic acid and formaldehyde ( $1 \mathrm{mmol}$ trioxymethylene is equivalent to $3 \mathrm{mmol}$ formaldehyde, and $1 \mathrm{mmol}$ dimsethoxymethane is equivalent to $1 \mathrm{mmol}$ formaldehyde) with a ratio of $15.25 \mathrm{mmol}$ to $6.1 \mathrm{mmol}$ was fed into the reactor. The reaction temperature is $360^{\circ} \mathrm{C}$ and the total carrier flow rate is $40 \mathrm{~mL} / \mathrm{min}$ (2.25 vol. $\% \mathrm{O}_{2}$ in $\mathrm{N}_{2}$ ). Clearly, both HCHO-based (AA + MA) yield (71.5\%) and HAc-based (AA + MA) selectivity $(61.3 \%)$ were found to be higher when formalin was used as FA source. According to our previous studies, the presence of water and methanol (as a stabilizing agent) in formalin was beneficial for (AA + MA) production. 


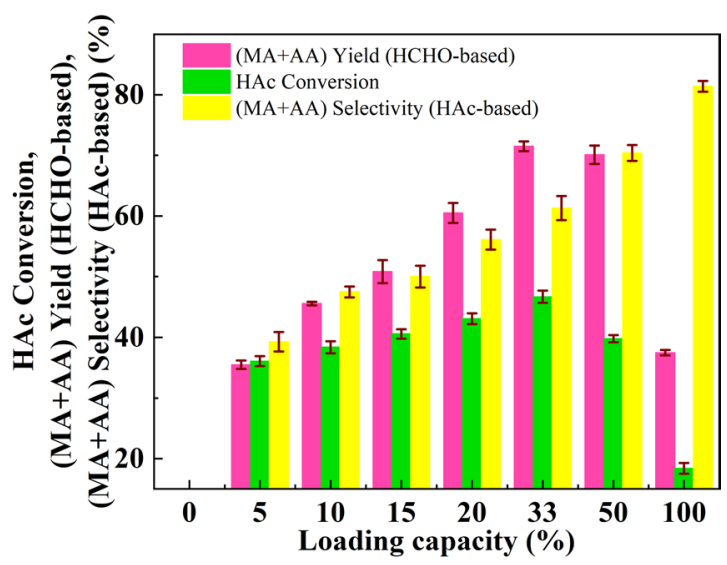

Figure 6. Effect of VPO loading on catalyst performance. $\mathrm{T}=360^{\circ} \mathrm{C}, \mathrm{HAc} / \mathrm{HCHO}=2.5 / 1(n / n)$, carrier flow rate $=40 \mathrm{~mL} / \mathrm{min}$, oxygen concentration $=2.25 \mathrm{vol} . \%, \mathrm{LHSV}=0.44 \mathrm{~mL} \cdot \mathrm{h}^{-1} \cdot \mathrm{g}_{\mathrm{cat}}{ }^{-1}$.

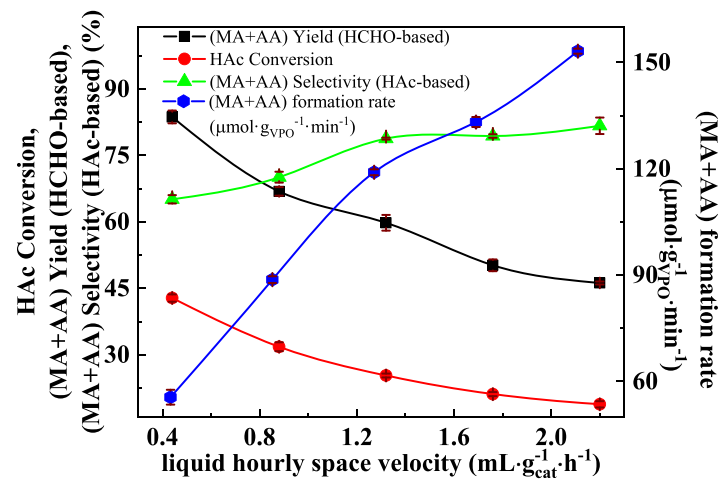

Figure 7. Effect of LHSV on the catalytic performance of $33 \%-\mathrm{VPO} / \mathrm{MCF} . \mathrm{T}=360^{\circ} \mathrm{C}, \mathrm{HAc} / \mathrm{HCHO}=3 / 1(n / n)$, carrier flow rate $=40 \mathrm{~mL} / \mathrm{min}$, oxygen concentration $=4.5 \mathrm{vol} . \%$ in the carrier.

In cause dimethoxymethane was used as FA source, the highest HAc conversion (64.3\%) was obtained but the (AA + MA) selectivity (HAc-based) was the lowest (29.5\%). A lot of methanol was formed as dimethoxymethane was fed, and plentiful methyl acetate was generated. The influence of $\mathrm{HAc} / \mathrm{HCHO}$ ratio on catalytic performance was studied (Supplementary Information, Fig. S4). Notably, the catalytic activity was dependent on the ratio of $\mathrm{HAc}$ to HCHO in the feedstock. The yield of (AA + MA) (HCHO-based) and (AA+MA) selectivity (HAc-based) increased significantly with increasing $\mathrm{HAc} / \mathrm{HCHO}$ ratio till $3 / 1$ and then nearly maintained with further increasing $\mathrm{HAc} / \mathrm{HCHO}$ ratio, indicating a maximum condensation between $\mathrm{HAc}$ and $\mathrm{HCHO}$ can be achieved at a HAc/ $\mathrm{HCHO}$ ratio being 3 over the current catalyst. On the other hand, the HAc conversion decreased continuously with increasing $\mathrm{HAc} / \mathrm{HCHO}$ ratio till 4/1. Therefore, a fixed $\mathrm{HAc} / \mathrm{HCHO}$ ratio of $3 / 1$ was adopted in the following studies.

Effect of operating parameters. The influence of carrier flow rate, oxygen concentration, and liquid hourly space velocity (LHSV) on catalyst performance was investigated over 33\%-VPO/MCF and the results are shown in Figs. S5 and S6 (Supplementary Information), and 7, respectively. The data in Fig. S5 (Supplementary Information) demonstrate that the carrier flow rate could have a direct impact on the activity: the (AA + MA) selectivity (HAc-based) increases while the HAc conversion decreases continuously with increasing carrier flowrate, and the highest (AA + MA) yield ( $\mathrm{HCHO}$-based) and (AA + MA) formation rate was achievable (ca. 64.7\% and $42.9 \mu \mathrm{mol} \cdot \mathrm{g}_{\mathrm{VPO}}{ }^{-1} \cdot \mathrm{min}^{-1}$ ) when the $\mathrm{N}_{2}$ flowrate raises from 20 to $40 \mathrm{~mL} / \mathrm{min}$. Longer contact time would favor deeper conversion of the target products, whereas short contact time could lead to quick release of active sites and accelerate reaction cycles ${ }^{45}$.

Furthermore, the gaseous oxygen content in the feed shows a critical impact on the reaction: it particularly tunes the oxidation state of surface $\mathrm{V}$ species and thus the surface acidity and the overall catalyst activity and durability as a result. As shown in Fig. S6, the HAc conversion increases while the (AA + MA) selectivity (HAc-based) decreases continuously with increasing co-fed oxygen concentration. At a co-fed oxygen concentration being $4.5 \%$ by volume, the $(\mathrm{AA}+\mathrm{MA})$ yield $(\mathrm{HCHO}-$ based $)$ and $(\mathrm{AA}+\mathrm{MA})$ formation rate turned to be $83.7 \%$ and $55.5 \mu \mathrm{mol} \cdot \mathrm{g}_{\mathrm{VPO}}{ }^{-1} \cdot \mathrm{min}^{-1}$, respectively. The higher the concentration of oxygen in the feed, the higher the degree of over-oxidation of the desired products as well as HAc. 


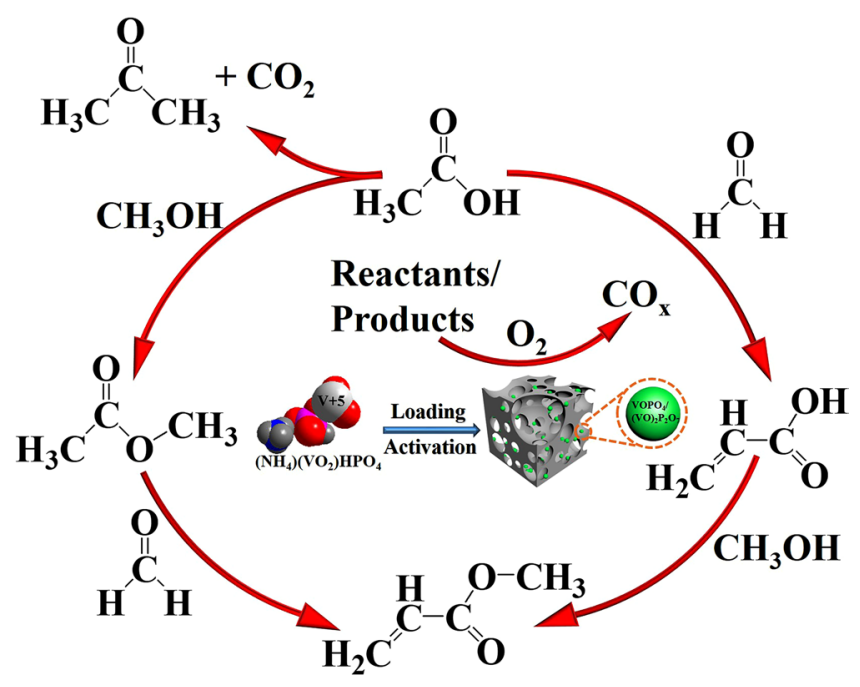

Scheme 1. An overview of catalyst design and the involved reaction routes.

The influence of liquid hourly space velocity (LHSV) on catalytic performance was also investigated over $33 \%$-VPO/MCF (Fig. 7). As the LHSV varies from 0.44 to $2.22 \mathrm{~mL} \cdot \mathrm{h}^{-1} \cdot \mathrm{g}_{\text {cat }}{ }^{-1}$, the HCHO-based (AA + MA) yield and HAc conversion decline simultaneously, whereas the (MA + AA) selectivity (HAc-based) and (AA + MA) formation rate increase to $81.7 \%$ and $153.2 \mu \mathrm{mol} \cdot \mathrm{g}_{\mathrm{VPO}}{ }^{-1} \cdot \mathrm{min}^{-1}$, respectively. Note that increase in LHSV would effectively reduce the relative oxygen concentration in the feed, which in turn suppresses the over-oxidation route.

To further study the catalytic performance for the representative catalysts, the catalysts of $5 \%-\mathrm{VPO} / \mathrm{MCF}$, 33\%-VPO/MCF, 50\%-VPO/MCF, and unsupported VPO were evaluated under the optimized conditions (carrier flow rate $=40 \mathrm{~mL} / \mathrm{min}^{-1}, \mathrm{~T}=360^{\circ} \mathrm{C}$, oxygen concentration $=4.5 \%$ ). The data of HCHO-based yield, HAc conversion, and selectivity as well as carbon balance were determined over the four representatives, the results were presented in Table S4 (Supplementary Information). Obviously, the (MA + AA) selectivity as well as carbon balance was enhanced with increasing VPO loading. However, the HAc conversion and (MA + AA) yield first increases with increasing VPO loading up to $33 \%$ and then declines with further increasing VPO content. According to the XPS and $\mathrm{NH}_{3}$-TPD investigations, the acid site density on catalyst surface mainly affect the HAc conversion, and an optimized VPO loading could result in a maximized acid site density through the auto regulation of $\mathrm{V}^{4+} /$ $\mathrm{V}^{5+}$ ratio.

To further understand the effect of textural property of support on catalytic activity, other two mesoporous silica, i.e., MCM-41 and SBA-15, were used to prepare the 33\%-VPO/MCM-41 and 33\%-VPO/SBA-15 catalysts, and the detailed results are shown in Table S5.33\%-VPO/SBA-15 outperforms 33\%-VPO/MCM-41, but both are inferior to $33 \%$-VPO/MCF. In terms of the textural/framework structure features of the three distinct meso-structured materials, the MCF is $3 \mathrm{D}$ porous, comprising uniform spherical cells interconnected by windows with a narrow size distribution. MCM-41 and SBA-15 are 2D ordered mesoporous material. The pore diameter of MCM-41 and SBA-15 is 3-5 nm and 6-11 nm, respectively; whereas the pore diameter of MCF could be up to $50 \mathrm{~nm}^{36}$. The MCF provides more open porous network, allowing accommodation of more VPO guest species, favorable for better molecule accessibility and enhanced mass transfer in the catalyst ${ }^{35,36}$.

Catalyst durability. The durability of $33 \%$-VPO/MCF was explored at $360^{\circ} \mathrm{C}$ for approximately $140 \mathrm{~h}$, with the LHSV, carrier flow rate, and oxygen concentration being $0.44 \mathrm{~mL} \cdot \mathrm{h}^{-1} \cdot \mathrm{g}_{\text {cat }}{ }^{-1}, 40 \mathrm{~mL} / \mathrm{min}$, and $4.5 \%$, respectively (Supplementary Information, Fig. S7). Slow deactivation was observed within a time-on-stream of $100 \mathrm{~h}$. After that, the catalyst was treated by an air flow $\left(30 \mathrm{~mL} \cdot \mathrm{min}^{-1}\right)$ for $5 \mathrm{~h}$ at the reaction temperature. The activity was essentially recovered. The regenerated catalyst deactivated similarly within an extended period of 40-h.

To verify the possible changes in surface oxidation state and acid site density of catalyst within the reaction procedure, the catalyst used for different time on stream $(5,25$, and $72 \mathrm{~h}$, respectively) was characterized by means of XPS and $\mathrm{NH}_{3}$-TPD. The results were summarized in Tables S6-8 (Supplementary Information). Obviously, the (MA + AA) yield (HCHO-based) and HAc conversion decreases gradually. On the other hand, the (MA + AA) selectivity declines insignificantly (the inset, Supplementary Information, Fig. S7), demonstrating that catalyst deactivation would be mostly resulted from conversion other than selectivity drop. As Table S7 showed (Supplementary Information), the V species of low oxidation state emerged with time on stream, indicating that the $\mathrm{V}^{5+}$ was gradually reduced to $\mathrm{V}^{4+}$ and $\mathrm{V}^{3+}$. As Table $\mathrm{S} 8$ (Supplementary Information) indicated, the medium strong and total acidity gradually decrease with extended reaction period, but the strong acidity essentially retained. Clearly, variation in the surface $\mathrm{V}$ oxidation state mainly accounts for the medium strong acidity, very influential on the catalytic performance of the target reaction ${ }^{20,37}$.

Based on the reactants fed and products detected, the involved reaction routes are illustrated in Scheme 1 as well as Eqs. 1-6. HAc reacts with HCHO through nucleophilic addition and dehydration to produce AA (Eq. 1) ${ }^{16}$. This is the main reaction route over the current catalyst system. There are minor side reactions associated with 
HAc, including bimolecular dehydration and decarboxylation of HAc to acetone and esterification of HAc with methanol to methyl acetate (Eqs. 2 and 3) ) $^{31}$, the latter can react with HCHO to MA (Eq. 4). MA can also be generated via esterification of AA with methanol (Eq. 5) ${ }^{28} \cdot \mathrm{CO}_{x}$ are produced due to the deep oxidation of reactants/ products (Eq. 6), and their contents are sensitive to the oxygen concentration in the feed.

$$
\begin{gathered}
\mathrm{CH}_{3} \mathrm{COOH}+\mathrm{HCHO} \rightarrow \mathrm{CH}_{2}(\mathrm{OH}) \mathrm{CH}_{2} \mathrm{COOH} \rightarrow \mathrm{CH}_{2}=\mathrm{CHCOOH}+\mathrm{H}_{2} \mathrm{O} \\
2 \mathrm{CH}_{3} \mathrm{COOH} \rightarrow \mathrm{CH}_{3} \mathrm{COCH}_{3}+\mathrm{CO}_{2}+\mathrm{H}_{2} \mathrm{O} \\
\mathrm{CH}_{3} \mathrm{COOH}+\mathrm{CH}_{3} \mathrm{OH} \rightarrow \mathrm{CH}_{3} \mathrm{COOCH}_{3}+\mathrm{H}_{2} \mathrm{O} \\
\mathrm{CH}_{3} \mathrm{COOCH}_{3}+\mathrm{HCHO} \rightarrow \mathrm{CH}_{2}=\mathrm{CHCOOCH}_{3}+\mathrm{H}_{2} \mathrm{O} \\
\mathrm{CH}_{2}=\mathrm{CHCOOH}^{\mathrm{CH}} \mathrm{CH}_{3} \mathrm{OH} \rightarrow \mathrm{CH}_{2}=\mathrm{CHCOOCH}_{3}+\mathrm{H}_{2} \mathrm{O} \\
\mathrm{CH}_{3} \mathrm{COOH} / \mathrm{HCHO} / \text { Products }+\mathrm{O}_{2} \rightarrow \mathrm{CO}_{x}
\end{gathered}
$$

Concluding remarks. The MCF supported vanadium phosphorus oxide with a unique feature of self-regulation of phase constitution and thus surface $\mathrm{V}^{4+} / \mathrm{V}^{5+}$ ratio and acid-base property was technically feasibly fabricated for the first time by employing a specific VPO precursor of $\mathrm{NH}_{4}\left(\mathrm{VO}_{2}\right) \mathrm{HPO}_{4}$ dispersed on MCF. The resulting materials were found to be efficient to catalyze the gas phase $\mathrm{HCHO}-\mathrm{HAc}$ condensation to AA (MA). The study is the first example to achieve self-regulation of surface $\mathrm{V}^{4+}$ and $\mathrm{V}^{5+}$ state as well as surface acidity and basicity via simultaneous reduction between the $\mathrm{V}^{5+}$ and $\mathrm{NH}_{3}$ upon catalyst activation: the released $\mathrm{NH}_{3}$ can be captured on the MCF support surface which promotes the redox reaction. Characterizations revealed details about VPO phase structure, surface P/V ratio, surface concentration and oxidation state of V element, reduction behavior of VPO entities, and surface acidity-basicity of VPO/MCFs with respect to the unsupported VPO as well as MCF support. The significant recognition is that both $\mathrm{B} / \mathrm{L}$ acidity together with weak basicity is critical for forming the desired products. Through simply tuning the VPO loading on MCF, very efficient and selective supported VPO system is achievable: over 33\%-VPO/ $\mathrm{MCF}$, the (AA + MA) yield of $83.7 \%$ (HCHO-based) or a (AA + MA) selectivity of $81.7 \%$ (HAc-based) are obtained employing the optimized conditions. This sort of catalyst is relatively durable under the comparatively milder conditions, and in addition, readily reproducible with the help of easy-treatment by air at the identical temperature of reaction.

\section{Experimental and Methods}

Chemicals. The following chemicals, 1,3,5-trimethylbezene (TMB), Pluronic P123 triblock copolymer $\left(\mathrm{EO}_{20} \mathrm{PO}_{70} \mathrm{EO}_{20}\right.$, averaged molecular weight $\left.=5800\right)$, tetraethyl orthosilicate (TEOS), ammonium fluoride $\left(\mathrm{NH}_{4} \mathrm{~F}\right)$, acetic acid $(\geq 99.0 \%)$, phosphoric acid $\left(\mathrm{H}_{3} \mathrm{PO}_{4}, 85 \%\right)$, ammonium metavanadate $\left(\mathrm{NH}_{4} \mathrm{VO}_{3}\right)$ were purchased in analytical grade. The commercial HCHO solution (37 wt.\%) comprises a small fraction (ca. 6\%) of methanol, to stabilize the $\mathrm{HCHO}$ component.

Catalyst preparation. The MCF support was prepared according to the procedures described in literature ${ }^{57,58}$. MCF-supported VPO samples were prepared via a simple impregnation approach which does not employ any organic solvent. $\mathrm{NH}_{4} \mathrm{VO}_{3}$ of $2.34 \mathrm{~g}$ was dissolved in $90 \mathrm{~mL}$ deionized water, then certain amount of MCF was added at a $\mathrm{V} / \mathrm{Si}$ atomic ratio of $1 / 19,1 / 2,1 / 1$ and $1 / 0$, respectively. Being stirred at $90^{\circ} \mathrm{C}$ for $6 \mathrm{~h}$, phosphoric acid (85\%) with an atomic $\mathrm{P} / \mathrm{V}$ ratio being 1 was added into the solution. 20 minutes later, the brown mixture was dried at $60^{\circ} \mathrm{C}$ under vacuum, further calcined at $400^{\circ} \mathrm{C}$ for $16 \mathrm{~h}$ in an air flow $(60 \mathrm{~mL} / \mathrm{min})$.

Characterization. X-ray powder diffraction (XRD), Raman, BET, XPS, Pyridine-adsorption FTIR, $\mathrm{H}_{2}$-TPR, as well as $\mathrm{NH}_{3} / \mathrm{CO}_{2}$-TPD were conducted on the Philips X'Pert MPD Pro X-ray diffractometer, Renishanplc-Reflex Raman spectrometer, ASAP 2020 material physical structure determinator, PHI5000 Versa Probe instrument, Bruker TENSOR 27 spectrometer, and a GC with a TCD detector, respectively. The experimental details were described in SI (Supplementary Information).

Catalyst evaluation. Catalytic activity was evaluated under atmospheric pressure at $360^{\circ} \mathrm{C}$ which was optimized previously. The catalyst amount was $3 \mathrm{~g}$, carrier flow rate was $20-50 \mathrm{~mL} / \mathrm{min}\left(0-6.8 \mathrm{vol} . \% \mathrm{O}_{2}\right.$ in $\left.\mathrm{N}_{2}\right)$. The mixed HAc and HCHO solution (molar ratio = 1-4) was fed into the reactor and the overall feed rate adjusted in the range of $1.33-6.65 \mathrm{~mL} \cdot \mathrm{h}^{-1}\left(\mathrm{HCHO}\right.$ feed rate $\left.=6.1-30.5 \mathrm{mmol} \cdot \mathrm{h}^{-1}\right)$. The products were analyzed by a GC. The details about experimental set-up as well as the information how to calculate the parameters of $Y_{A A+M A}, X_{H A C}$, $S_{A A+M A}, F R_{A A+M A}$ and overall carbon balance were provided in SI (Supplementary Information). The experimental error was determined based on the repeated measurements, and indicated in the reaction performance profiles. Generally, the experimental error was found to be less than $\pm 2 \%$.

Received: 19 July 2019; Accepted: 14 October 2019;

Published online: 18 November 2019 


\section{References}

1. Guo, X. P. et al. Catalysts, Process Optimization, and Kinetics for the Production of Methyl Acrylate over Vanadium Phosphorus Oxide Catalysts. Ind. Eng. Chem. Res. 56, 5860-5871 (2017).

2. Cools, P. et al. Acrylic Acid Plasma Coated 3D Scaffolds for Cartilage tissue engineering applications. Sci. Rep. 8, 3830-3844 (2018).

3. $\mathrm{Wu}, \mathrm{Y}$. Q. et al. A green route to prepare fluorescent and absorbent nano-hybrid hydrogel for water detection. Sci. Rep. 7, 4380-4390 (2017).

4. Lin, M. M. Selective oxidation of propane to acrylic acid with molecular oxygen. Appl. Catal. A: Gen. 207, 1-16 (2001).

5. Yang, X. J., Feng, R. M., Ji, W. J. \& Au, C. T. Characterization and evaluation of Mo-V-Te-Nb mixed metal oxide catalysts fabricated via hydrothermal process with ultrasonic pretreatment for propane partial oxidation. J. Catal. 253, 57-65 (2008).

6. Mizuno, N., Tateishi, M. \& Iwamoto, M. Pronounced catalytic activity of $\mathrm{Fe}_{0.08} \mathrm{Cs}_{25} \mathrm{H}_{126} \mathrm{PVMo}_{11} \mathrm{O}_{40}$ for direct oxidation of propane into acrylic acid. Appl. Catal. A: Gen. 128, L165-L170 (1995).

7. Takashi, U., Hiroya, N., Yukio, K. \& Shin, W. Method for producing an unsaturated carboxylic acid (US Patent 5380933, 1995).

8. Lin, M. M. Complex metal-oxide catalysts for selective oxidation of propane and derivatives I. Catalysts preparation and application in propane selective oxidation to acrylic acid. Appl. Catal. A: Gen. 250, 305-318 (2003).

9. Botella, P., López Nieto, J. M., Solsona, B., Mifsud, A. \& Márquez, F. The Preparation, Characterization, and Catalytic Behavior of MoVTeNbO Catalysts Prepared by Hydrothermal Synthesis. J. Catal. 209, 445-455 (2002).

10. Fang, W., Ge, Q. J., Yu, J. F. \& Xu, H. Y. Catalytic Selective Oxidation of Propane to Acrylic Acid in a Fixed-Bed Reactor with an $\mathrm{O}_{2}$ Distributor. Ind. Eng. Chem. Res. 50, 1962-1967 (2011).

11. d'Alnoncourt, R. N. et al. The reaction network in propane oxidation over phase-pure MoVTeNb M1 oxide catalysts. J. Catal. 311 , 369-385 (2014).

12. Jo, B. Y., Kum, S. S. \& Moon, S. H. Performance of WOx-added Mo-V-Te-Nb-O catalysts in the partial oxidation of propane to acrylic acid. Appl. Catal. A: Gen. 378, 76-82 (2010).

13. Chieregato, A. et al. Structure-Reactivity Correlations in Vanadium-Containing Catalysts for One-Pot Glycerol Oxidehydration to Acrylic Acid. Chem. Sus. Chem. 10, 234-244 (2017).

14. Chieregato, A. et al. Multielement crystalline and pseudocrystalline oxides as efficient catalysts for the direct transformation of glycerol into acrylic acid. Chem. Sus. Chem. 8, 398-406 (2015).

15. Dolores Soriano, M. et al. Tungsten-Vanadium mixed oxides for the oxidehydration of glycerol into acrylic acid. Green Chem. 13, 2954-2962 (2011).

16. Ai, M. Vapor-phase aldol condensation of formaldehyde with acetic acid on $\mathrm{V}_{2} \mathrm{O}_{5}-\mathrm{P}_{2} \mathrm{O}_{5}$ catalysts. J. Catal. 107, 201-208 (1987).

17. Bailey, O. H., Montag, R. A. \& Yoo, J. S. Methacrylic acid synthesis I. Condensation of propionic acid with formaldehyde over alkali metal cation on silica catalysts. Appl. Catal. A: Gen. 88, 163-177 (1992)

18. Ai, M., Fujihashi, H., Hosoi, S. \& Yoshida, A. Production of methacrylic acid by vapor-phase aldol condensation of propionic acid with formaldehyde over silica-supported metal phosphate catalysts. Appl. Catal. A: Gen. 252, 185-191 (2003).

19. Tai, J. R. \& Davis, R. J. Synthesis of methacrylic acid by aldol condensation of propionic acid with formaldehyde over acid-base bifunctional catalysts. Catal. Today 123, 42-49 (2007).

20. Feng, X. Z. et al. Renewable production of acrylic acid and its derivative: New insights into the aldol condensation route over the vanadium phosphorus oxides. J. Catal. 314, 132-141 (2014).

21. Ai, M. Formation of methyl methacrylate by condensation of methyl propionate with formaldehyde over silica-supported cesium hydroxide catalysts. Appl. Catal. A: Gen. 288, 211-215 (2005).

22. Yan, J. B. et al. Vapor phase condensation of methyl acetate with formaldehyde to preparing methyl acrylate over cesium supported SBA-15 catalyst. J. Ind. and Eng. Chem. 25, 344-351 (2015).

23. Wang, Y. N. et al. Preparation of Cs-La-Sb/SiO ${ }_{2}$ catalyst and its performance for the synthesis of methyl acrylate by aldol condensation. RSC Adv. 5, 32826-32834 (2015).

24. Centi, G., Cavani, F. \& Trifirò, F. Selective Oxidation by Heterogeneous Catalysis, in Fundamental and Applied Catalysis, Kluwer Academic/Plenum Publishers, New York (2001).

25. Hodnett, B. K. Heterogeneous Catalytic Oxidation, John Wiley \& Sons Ltd, West Sussex (2000).

26. Yang, D., Sararuk, C., Suzuki, K., Li, Z. X. \& Li, C. S. Effect of calcination temperature on the catalytic activity of VPO for aldol condensation of acetic acid and formalin. Chem. Eng. J. 300, 160-168 (2016).

27. Wang, F., Dubois, J. L. \& Ueda, W. Catalytic dehydration of glycerol over vanadium phosphate oxides in the presence of molecular oxygen. J. Catal. 268, 260-267 (2009).

28. Zhao, H., Zuo, C. C., Yang, D., Li, C. S. \& Zhang, S. J. Effects of Support for Vanadium Phosphorus Oxide Catalysts on Vapor-Phase Aldol Condensation of Methyl Acetate with Formaldehyde. Ind. Eng. Chem. Res. 55, 12693-12702 (2016).

29. Yang, D. et al. Effect of Metal Ion in Bulk VPO in Aldol Condensation of Formaldehyde and Methyl Acetate to Methyl Acrylate. Ind. Eng. Chem. Res. 57, 93-100 (2018).

30. Yang, D. et al. Reaction of formalin with acetic acid over vanadium-phosphorus oxide bifunctional catalyst. Ind. Eng. Chem. Res. 54, 6865-6873 (2015).

31. Hu, J. et al. Aldol condensation of acetic acid with formaldehyde to acrylic acid over $\mathrm{SiO}_{2^{-}}$, SBA-15-, and HZSM-5-supported V-P-O catalysts. J. Ind. and Eng. Chem. 40, 145-151 (2016).

32. Wang, X. B., Jiang, X. F. \& Bando, Y. Blowing Route towards Advanced Inorganic Foams. Bull. Chem. Soc. Jpn. 92, 245-263 (2019).

33. Wang, H. et al. Visible-light-driven removal of tetracycline antibiotics and reclamation of hydrogen energy from natural water matrices and wastewater by polymeric carbon nitride foam. Water Res. 144, 215-225 (2018).

34. Park, S. et al. Direct synthesis of hydrogen peroxide from hydrogen and oxygen over palladium catalyst supported on $\mathrm{H}_{3} \mathrm{PW}_{12} \mathrm{O}_{40}{ }^{-}$ incorporated MCF silica. J. Mol. Catal. A: Chem. 336, 78-86 (2011).

35. Wei, L. et al. Fischer-Tropsch synthesis over a 3D foamed MCF silica support: Toward a more open porous network of cobalt catalysts. J. Catal. 340, 205-218 (2016).

36. Liu, Y. M. et al. Structure and catalytic properties of vanadium oxide supported on mesocellulous silica foams (MCF) for the oxidative dehydrogenation of propane to propylene. J. Catal. 239, 125-136 (2006).

37. Liu, J. et al. Precisely phase-modulated VPO catalysts with enhanced inter-phase conjunction for acrylic acid production through the condensation of acetic acid and formaldehyde. J. Catal. 374, 171-182 (2019).

38. Abdelouahab, F. B., Olier, R., Guilhaume, N., Lefebvre, F. \& Volta, J. C. A study by in situ laser Raman spectroscopy of VPO catalysts for n-butane oxidation to maleic anhydride I. Preparation and characterization of pure reference phases. J. Catal. 134, 151-167 (1992).

39. Preston, C. M. \& Adams, W. A. A laser Raman spectroscopic study of aqueous orthophosphate salts. J. Phys. Chem. 83, 814-821 (1979).

40. Reddy, B. M., Ganesh, I. \& Reddy, E. P. Study of dispersion and thermal stability of $\mathrm{V}_{2} \mathrm{O}_{5} / \mathrm{TiO}_{2}-\mathrm{SiO}_{2}$ catalysts by XPS and other techniques. J. Phys. Chem. B 101, 1769-1774 (1997).

41. Bukhtiyarov, V. I. XPS and SIMS characterization. Catal. Today 56, 403-413 (2000).

42. Kasperkiewicz, J., Kovacich, J. A. \& Lichtman, D. XPS studies of vanadium and vanadium oxides. J. Electron. Spectrosc. Relat. Phenom. 32, 123-132 (1983).

43. Igarashi, H., Tsuji, K., Okuhara, T. \& Misono, M. Effects of consecutive oxidation on the production of maleic anhydride in butane oxidation over four kinds of well-characterized vanadyl pyrophosphates. J. Phys. Chem. 97, 7065-7071 (1993). 
44. Wang, X. S. et al. Novel modifications in preparing vanadium phosphorus oxides and their applications for partial oxidation of n-butane. J. Mol. Catal. A: Chem. 206, 261-268 (2003).

45. Overbeek, R. A., Pekelharing, A. R. C. J., van Dillen, A. J. \& Geus, J. W. Preparation, characterization and testing of newly developed silica-supported V-P-O catalysts. Appl. Catal. A: Gen. 135, 231-248 (1996).

46. Overbeek, R. A. et al. Preparation, characterization and testing of newly developed titania supported V-P-O catalysts. Appl. Catal. A: Gen. 135, 209-230 (1996).

47. Taufiq-Yap, Y. H., Goh, C. K., Hutchings, G. J., Dummer, N. \& Bartley, J. K. Effects of mechanochemical treatment to the vanadium phosphate catalysts derived from $\mathrm{VOPO}_{4} \cdot 2 \mathrm{H}_{2} \mathrm{O}$. J. Mol. Catal. A: Chem. 260, 24-31 (2006).

48. Abon, M., Herrmann, J. M. \& Volta, J. C. Correlation with the redox $\mathrm{V}^{5+} / \mathrm{V}^{4+}$ ratio in vanadium phosphorus oxide catalysts for mild oxidation of n-butane to maleic anhydride. Catal. Today 71, 121-128 (2001).

49. Sing, K. S. W. E. et al. Reporting physisorption data for gas/solid systems with special reference to the determination of surface area and porosity. Pure Appl. Chem. 57, 603-619 (1985).

50. Barreau, M., Courtois, X. \& Can, F. FT-IR spectroscopy study of HNCO adsorption and hydrolysis over oxide-based samples dedicated to deNOx processes. Appl. Catal. A: Gen. 552, 147-153 (2018).

51. Tamura, M., Shimizu, K. \& Satsuma, A. Comprehensive IR study on acid/base properties of metal oxides. Appl. Catal. A: Gen. 433434, 135-145 (2012).

52. Zaki, M. I., Hasan, M. A., Al-Sagheer, F. A. \& Pasupulety, L. In situ FTIR spectra of pyridine adsorbed on $\mathrm{SiO}_{2}-\mathrm{Al}_{2} \mathrm{O}_{3}, \mathrm{TiO}_{2}, \mathrm{ZrO}_{2}$ and $\mathrm{CeO}_{2}$ : general considerations for the identification of acid sites on surfaces of finely divided metal oxides. Colloids and Surfaces A: Physicochem. Eng. Aspects 190, 261-274 (2001).

53. Flura, A., Can, F., Courtois, X., Royer, S. \& Duprez, D. High-surface-area zinc aluminate supported silver catalysts for lowtemperature SCR of NO with ethanol. Appl. Catal. B: Environ. 126, 275-289 (2012).

54. Wang, B. et al. Hydrotreating performance of FCC diesel and dibenzothiophene over NiMo supported zirconium modified AlTUD-1 catalysts. Ind. Eng. Chem. Res. 57, 11868-11882 (2018).

55. Wang, A. L. et al. Aldol condensation of acetic acid with formaldehyde to acrylic acid over Cs (Ce, $\mathrm{Nd}) \mathrm{VPO} / \mathrm{SiO}_{2}$ catalyst. RSC Adv . 7, 48475-48485 (2017).

56. Ma, Z. L. et al. A green route to methyl acrylate and acrylic acid by an aldol condensation reaction over H-ZSM-35 zeolite catalysts. Chem. Commun. 53, 9071-9074 (2017).

57. Schmidt-Winkel, P., Glinka, C. J. \& Stucky, G. D. Microemulsion templates for mesoporous silica. Langmuir 16, 356-361 (2000).

58. Birkeland, K. E. et al. Supported VPO catalysts for selective oxidation of butane. II. Characterization of $\mathrm{VPO} / \mathrm{SiO}_{2}$ catalysts. J. Phys. Chem. B 101, 6895-6902 (1997).

\section{Acknowledgements}

The financial support of NSFC (21673112) is greatly appreciated.

\section{Author contributions}

Jun Liu, Xinzhen Feng and Weijie Ji designed this research; Jun Liu, Peiwen Xu, Pengcheng Wang, Zhijia Xu and Xinzhen Feng conducted research; Jun Liu and Xinzhen Feng analyzed data; Jun Liu and Weijie Ji wrote the paper; Chak-Tong Au modified the paper; Jun Liu and Pengcheng Wang drew the Scheme 1; Jun Liu, Xinzhen Feng, Weijie Ji and Chak-Tong Au edited the whole manuscript.

\section{Competing interests}

The authors declare no competing interests.

\section{Additional information}

Supplementary information is available for this paper at https://doi.org/10.1038/s41598-019-53180-8.

Correspondence and requests for materials should be addressed to X.F. or W.J.

Reprints and permissions information is available at www.nature.com/reprints.

Publisher's note Springer Nature remains neutral with regard to jurisdictional claims in published maps and institutional affiliations.

(c) (1) Open Access This article is licensed under a Creative Commons Attribution 4.0 International

License, which permits use, sharing, adaptation, distribution and reproduction in any medium or format, as long as you give appropriate credit to the original author(s) and the source, provide a link to the Creative Commons license, and indicate if changes were made. The images or other third party material in this article are included in the article's Creative Commons license, unless indicated otherwise in a credit line to the material. If material is not included in the article's Creative Commons license and your intended use is not permitted by statutory regulation or exceeds the permitted use, you will need to obtain permission directly from the copyright holder. To view a copy of this license, visit http://creativecommons.org/licenses/by/4.0/.

(C) The Author(s) 2019 